\title{
Adubação nitrogenada de cobertura no feijoeiro, em plantio direto e convencional
}

\author{
Rogério Farinelli(1), Leandro Borges Lemos ${ }^{(1)}$, Fernando Guido Penariol(2), Milton Maia Egéa ${ }^{(1)}$ \\ e Murilo Godoy Gasparoto(1)
}

\begin{abstract}
(1)Universidade Estadual Paulista, Fac. de Ciências Agronômicas, Dep. de Produção Vegetal, Caixa Postal 237, CEP $18610-307$ Botucatu, SP. E-mail: rfarinelli@fca.unesp.br, leandrobl@fca.unesp.br, mmegea@fca.unesp.br, mggasparoto@fca.unesp.br (2)Ministério da Agricultura, Pecuária e Abastecimento, Dep. de Fomento e Fiscalização da Produção Vegetal, CEP 70043-900 Brasília, DF. E-mail: fpenariol@agricultura.gov.br
\end{abstract}

Resumo - O objetivo deste trabalho foi avaliar o efeito da adubação nitrogenada em cobertura, sobre o desempenho agronômico do feijoeiro, nos sistemas convencional e plantio direto. O trabalho foi desenvolvido durante dois anos agrícolas, em um Nitossolo Vermelho, utilizando-se a sucessão aveia-preta/milheto/feijão cv. Pérola (outono-inverno, primavera e verão, respectivamente), em condição de sequeiro. Foi empregado o delineamento experimental de blocos ao acaso, em esquema de parcelas subdivididas, com quatro repetições. As parcelas foram representadas por sistemas de manejo de solo de preparo convencional e plantio direto, e as subparcelas por doses de adubação nitrogenada em cobertura (0, 40, 80, 120 e $160 \mathrm{~kg} \mathrm{ha}^{-1}$ de N), utilizando-se uréia como fonte de $\mathrm{N}$. A cultura do feijão responde às doses de $\mathrm{N}$ em cobertura, com maior produtividade de grãos, no segundo ano da sucessão aveia-preta/milheto/feijão, necessitando, porém, de doses mais elevadas no sistema de plantio direto.

Termos para indexação: Phaseolus vulgaris, doses de nitrogênio, sistema de manejo de solo, produtividade.

\section{Nitrogen topdressing in common bean in no tillage and conventional tillage system}

\begin{abstract}
The objective of this work was to evaluate the effect of nitrogen topdressing in common bean agronomic performance in no tillage and conventional tillage system. The work was developed during two seasons, in different years, in a Rhodic Kandiudox soil, using the succession black oat/pear millet/common bean cv. Perola (fall-winter, spring and summer, respectively), in no irrigated conditions. The experimental design was the randomized blocks in split plot design, with four replications. The parcels were represented by different soil tillage (conventional and no tillage), and the subparcels by doses of nitrogen applied in topdressing ( 0,40 , 80, 120 , and $160 \mathrm{~kg} \mathrm{ha}^{-1}$ of $\mathrm{N}$ ); urea was used as source of $\mathrm{N}$. Common bean crop has distinct responses to the doses of nitrogen in topdressing through the years of cultivation, with higher grain yield in the second year of the succession black oat/pearl millet/bean, needing, however, higher doses in no tillage system.
\end{abstract}

Index terms: Phaseolus vulgaris, doses of nitrogen, soil tillage system, productivity.

\section{Introdução}

O feijoeiro comum (Phaseolus vulgaris L.) é a espécie mais cultivada no mundo entre as demais do gênero Phaseolus, e o Brasil é seu maior produtor. Destaca-se também por ser uma importante fonte protéica na dieta humana. Apesar da baixa produtividade no país, em torno de $850 \mathrm{~kg} \mathrm{ha}^{-1}$, o feijoeiro vem sendo explorado numa diversidade de sistemas de produção, obtendo-se produtividades superiores a $3 \mathrm{mil}$ quilogramas por hectare (Yokoyama, 2002).

Entre os vários sistemas de produção, destaca-se o plantio direto que contribui para a melhoria da capacidade produtora do solo, conservando ou melhorando o ambiente. Esse sistema fundamenta-se no não-revolvimento do solo, em sua cobertura permanente e na rotação de culturas, podendo promover acréscimo de produtividade das culturas de grãos (Salton et al., 1998).

Os trabalhos disponíveis sobre o feijoeiro, nesse sistema de produção, são menos numerosos, em comparação com aqueles relativos às culturas de soja, trigo e milho (Balbino et al., 1996). Entretanto, é crescente o número de trabalhos com a cultura do feijão que confrontam os diversos sistemas de manejo de solo, visando a obter informações quanto ao ganho de 
produtividade no plantio direto, em relação a outros e, especialmente, ao preparo convencional (Stone \& Moreira, 2000, 2001; Arf et al., 2004).

No plantio direto, em comparação ao manejo de solo convencional, talvez exista a necessidade de se utilizar doses de nitrogênio maiores, em virtude dos efeitos da velocidade de decomposição e relação $\mathrm{C} / \mathrm{N}$ da palha, no processo de imobilização do nitrogênio. A competição dos microrganismos com o feijoeiro, especialmente nos estádios iniciais de desenvolvimento, e a grande absorção e extração do N pela planta, limitam a produtividade da cultura, mesmo que outros fatores de produção sejam otimizados (Arf, 1994; Rosolem, 1996; Siqueira \& Moreira, 2002).

Neste sentido, destaca-se a realização de trabalhos em que foi estudado o desempenho do feijoeiro sob adubação nitrogenada, em diversos sistemas de manejo de solo, nos quais alguns resultados mostraram resposta da cultura a doses de nitrogênio acima de $100 \mathrm{~kg} \mathrm{ha}^{-1}$ (Stone \& Moreira, 2001; Carvalho et al., 2003; Silva et al., 2003). Outros autores, como Silveira \& Damasceno (1993), Chidi et al. (2002) e Bordin et al. (2003) verificaram resposta de produtividade do feijoeiro entre 50 e $76 \mathrm{~kg} \mathrm{ha}^{-1} \mathrm{de} \mathrm{N}$.

O objetivo deste trabalho foi avaliar o efeito da adubação nitrogenada em cobertura, sobre o desempenho agronômico do feijoeiro, nos sistemas convencional e plantio direto.

\section{Material e Métodos}

O experimento foi instalado na Faculdade de Ciências Agronômicas - Unesp, Campus de Botucatu, SP, durante os anos agrícolas 2002/2003 e 2003/2004, num Nitossolo Vermelho distrófico (Embrapa, 1999). O clima, de acordo com a classificação de Köppen, é do tipo Cwa, subtropical, com verões quentes e úmidos, e invernos frios e secos.

A área experimental faz parte de um programa de estudos de longo prazo, a fim de comparar os sistemas de manejo de solo, utilizando-se o preparo convencional e o plantio direto. Iniciado em 1985, o programa utilizou a seqüência de culturas de trigo e soja até 1995 , tendo permanecido em pousio até 1999, quando a área foi ocupada por um experimento de milho nesses dois sistemas de manejo de solo, tendo ficado novamente em pousio, até a instalação deste trabalho.

Antes do feijoeiro, visando a realizar um sistema de sucessão de culturas para a produção de matéria seca, foram implantadas na área experimental, nos anos de 2002 e 2003, as culturas de aveia-preta (cultivar Comum), no período de outono-inverno, e milheto (cultivar BN 2), na primavera, ambas manejadas aos 60 dias depois da emergência, por meio de dessecação com glifosato na dose de $2,5 \mathrm{~L} \mathrm{ha}^{-1}$ de produto comercial.

A semeadura do feijoeiro, cultivar Pérola, foi realizada em 19/12/2002 e 18/12/2003, tendo o seu desenvolvimento ocorrido durante o período de verão, em condições de sequeiro, utilizando-se 18 sementes por metro de sulco, num espaçamento entre linhas de $0,45 \mathrm{~m}$. As sementes foram previamente tratadas com inseticida (thiamethoxan) e fungicida (carboxin + thiram), nas doses de 150 e $250 \mathrm{~mL}$ por $100 \mathrm{~kg}$ de sementes, respectivamente. Os demais tratamentos fitossanitários foram realizados mediante aplicação de produtos recomendados à cultura do feijão.

O delineamento experimental utilizado foi o de blocos ao acaso, em esquema de parcelas subdivididas, com quatro repetições. As parcelas foram representadas por dois sistemas de manejo de solo: preparo convencional, incluindo uma aração com discos, seguida de duas gradagens com grade niveladora; e plantio direto. As subparcelas foram formadas por cinco doses de adubação nitrogenada em cobertura $(0,40,80,120$ e $160 \mathrm{~kg} \mathrm{ha}^{-1}$ ), utilizando-se a uréia como fonte de N. Cada subparcela foi formada por dez linhas de feijão, em $8 \mathrm{~m}$ de comprimento, tendo sido consideradas úteis as oito linhas centrais, desprezando-se $0,5 \mathrm{~m}$ de cada extremidade.

Os resultados da análise química do solo, obtidos antes da instalação do experimento, na profundidade de 0-20 cm, nos dois sistemas de manejo de solo, encontram-se na Tabela 1. De acordo com os resultados da análise química do solo, no sistema de manejo convencional, e segundo recomendações de Ambrosano et al. (1997), foram empregados $300 \mathrm{~kg} \mathrm{ha}^{-1}$ da formulação

Tabela 1. Análise química do solo, nos sistemas de preparo convencional (PC) e plantio direto (PD), antes da instalação do experimento em 2002.

\begin{tabular}{|c|c|c|c|c|c|c|c|c|c|c|}
\hline $\begin{array}{l}\text { Profundidade/Sistema } \\
(\mathrm{cm})\end{array}$ & $\begin{array}{c}\mathrm{pH} \\
\left(\mathrm{CaCl}_{2}\right)\end{array}$ & $\begin{array}{c}\mathrm{MO} \\
\left(\mathrm{g} \mathrm{kg}^{-1}\right)\end{array}$ & $\begin{array}{l}\text { P resina } \\
\left(\mathrm{mg} \mathrm{dm}^{-3}\right)\end{array}$ & $\mathrm{H}+\mathrm{Al}$ & $\mathrm{K}$ & $\begin{array}{r}\mathrm{Ca} \\
--(\mathrm{m}\end{array}$ & $\begin{array}{c}\mathrm{Mg} \\
\left.\mathrm{dm}^{-3}\right)\end{array}$ & SB & CTC & $\begin{array}{l}\mathrm{V} \\
(\%)\end{array}$ \\
\hline $0-20(\mathrm{PC})$ & 5,3 & 32,0 & 72,4 & 47,7 & 3,4 & 40,0 & 18,0 & 61,4 & 109,0 & 56,0 \\
\hline 0-20 (PD) & 5,3 & 53,3 & 136,1 & 42,9 & 2,6 & 59,0 & 24,0 & 85,6 & 128,5 & 67,0 \\
\hline
\end{tabular}


4-20-10. As adubações de cobertura foram efetuadas no início do estádio fenológico $\mathrm{V}_{4}$, caracterizado pela presença da terceira folha trifoliolada, completamente aberta em 50\% das plantas (Fernández et al., 1985).

Por ocasião do florescimento pleno $\left(\mathrm{R}_{6}\right)$, na área útil de cada subparcela, foram coletadas dez plantas, ao acaso, para a avaliação da produção de matéria seca da parte aérea, como também a terceira folha trifoliolada do terço médio de 30 plantas, para obtenção do teor de nitrogênio, de acordo com recomendações de Ambrosano et al. (1997) e determinações seguindo a metodologia de Malavolta et al. (1997). Antes da colheita, foram avaliadas, em dez plantas coletadas ao acaso, na área útil de cada subparcela, os componentes da produção representados pelo número de vagens por planta, número de grãos por vagem e massa de 100 grãos.

A produtividade de grãos foi obtida pelo arranquio manual das plantas, contidas na área útil de cada subparcela, e posterior trilha mecânica, padronizandose o grau de umidade em $13 \%$.

O teor de proteína bruta (PB) nos grãos foi determinado pela fórmula $\mathrm{PB}=\mathrm{N}$ total $\mathrm{x} 6,25$, em que $\mathrm{N}$ total é o teor de $\mathrm{N}$ nos grãos, obtido de acordo com o método proposto por Sarruge \& Haag (1974).

Os resultados obtidos foram submetidos à análise de variância, utilizando-se o teste de Tukey a 5\% de probabilidade, para a comparação dos manejos de solo, e análise de regressão polinomial, para os estudos das doses de $\mathrm{N}$ em cobertura.

\section{Resultados e Discussão}

As doses de adubação nitrogenada interferiram na produção de matéria seca da parte aérea, com os valores ajustados à equação linear crescente, nos dois anos experimentais (Tabela 2), concordando com os resultados de Stone \& Moreira (2001) e Chidi et al. (2002), os quais submeteram as cultivares Aporé e Pérola, no período de inverno, a doses de 0 a $120 \mathrm{~kg} \mathrm{ha}^{-1}$ de $\mathrm{N}$ e 0 a $75 \mathrm{~kg} \mathrm{ha}^{-1}$ de $\mathrm{N}$, respectivamente. Tais resultados mostram que o $\mathrm{N}$ tem extrema importância na matéria seca, por se tratar de constituinte da molécula de clorofila e, portanto, tem influência na fotossíntese e promove o crescimento vegetativo do feijoeiro (Silveira \& Damasceno, 1993).

Verificou-se, também, que os teores foliares de $\mathrm{N}$ responderam de forma linear, no primeiro ano, e com função quadrática, no segundo ano, em relação às doses (Tabela 2). Silveira \& Damasceno (1993) e Carvalho et al. (2003) também verificaram essa resposta nas cultivares Carioca e IAC Carioca, no período de inverno, tanto em semeadura convencional quanto direta. Os valores encontrados, no presente trabalho, situaram-se dentro da faixa de suficiência indicada por Malavolta et al. (1997) e Ambrosano et al. (1997), e acima do nível crítico de $30 \mathrm{~g} \mathrm{~kg}^{-1}$, mesmo na ausência de adubação nitrogenada, corroborando os dados de Almeida et al. (2000). Tal resultado pode ser explicado pela sucessão de culturas utilizada que, provavelmente,

Tabela 2. Matéria seca da parte aérea, teor foliar de N, número de vagens por planta e número de grãos por vagem do feijoeiro, em função da adubação nitrogenada de cobertura, em dois sistemas de manejo de solo, em 2003 e 2004(1).

\begin{tabular}{|c|c|c|c|c|c|c|c|c|}
\hline \multirow[t]{2}{*}{ Tratamento } & \multicolumn{2}{|c|}{ Matéria seca $\left(\mathrm{kg} \mathrm{ha}^{-1}\right)$} & \multicolumn{2}{|c|}{ Teor foliar de $\mathrm{N}\left(\mathrm{g} \mathrm{kg}^{-1}\right)$} & \multicolumn{2}{|c|}{ Vagens por planta $\left(\mathrm{n}^{\circ}\right)$} & \multicolumn{2}{|c|}{ Grãos por vagem $\left(\mathrm{n}^{\mathrm{o}}\right)$} \\
\hline & $2003^{(2)}$ & $2004^{(3)}$ & $2003^{(4)}$ & $2004^{(5)}$ & 2003 & $2004^{(6)}$ & $2003^{(7)}$ & 2004 \\
\hline \multicolumn{9}{|l|}{ Manejo } \\
\hline $\mathrm{PC}$ & 2.634 & 2.579 & 38,50 & 37,40 & 5,90 & 10,80 & 4,40 & 4,30 \\
\hline $\mathrm{PD}$ & 2.529 & 2.661 & 34,60 & 39,20 & 6,50 & 8,90 & 4,40 & 4,40 \\
\hline Teste F & $0,20^{\mathrm{ns}}$ & $0,27^{\mathrm{ns}}$ & $8,01^{\mathrm{ns}}$ & $0,35^{\mathrm{ns}}$ & $0,70^{\mathrm{ns}}$ & $5,48^{\mathrm{ns}}$ & $0,006^{\mathrm{ns}}$ & $0,63^{\mathrm{ns}}$ \\
\hline $\mathrm{CV}(\%)$ & 28,30 & 20,30 & 11,80 & 25,20 & 33,30 & 27,10 & 13,50 & 6,40 \\
\hline \multicolumn{9}{|c|}{ Doses de $N\left(\mathrm{~kg} \mathrm{ha}^{-1}\right)$} \\
\hline 0 & 2.160 & 2.306 & 33,70 & 32,30 & 6,20 & 8,10 & 4,50 & 4,70 \\
\hline 40 & 2.427 & 2.523 & 36,50 & 36,80 & 6,50 & 9,40 & 4,90 & 4,30 \\
\hline 80 & 2.730 & 2.362 & 33,80 & 39,60 & 5,80 & 9,20 & 4,80 & 4,20 \\
\hline 120 & 2.807 & 2.887 & 38,10 & 42,10 & 6,60 & 10,20 & 4,00 & 4,00 \\
\hline 160 & 2.781 & 3.022 & 40,40 & 40,50 & 6,00 & 12,50 & 3,90 & 4,60 \\
\hline Teste $\mathrm{F}$ & $2,86^{*}$ & $2,63^{*}$ & $4,80^{* *}$ & $9,88^{* *}$ & $0,53^{\mathrm{ns}}$ & $6,08^{* *}$ & $3,79^{*}$ & $1,66^{\mathrm{ns}}$ \\
\hline$M \times D$ & $0,64^{\mathrm{ns}}$ & $0,72^{\mathrm{ns}}$ & $2,64^{\mathrm{ns}}$ & $0,27^{\mathrm{ns}}$ & $1,64^{\mathrm{ns}}$ & $0,60^{\mathrm{ns}}$ & $0,74^{\mathrm{ns}}$ & $1,95^{\mathrm{ns}}$ \\
\hline CV (\%) & 18,10 & 21,20 & 10,00 & 9,00 & 22,20 & 19,30 & 14,30 & 15,10 \\
\hline
\end{tabular}

(1)PC: preparo convencional; PD: plantio direto. ${ }^{(2)} \mathrm{y}=4,06 \mathrm{x}+2 \cdot 257 \mathrm{R}^{2}=0,84^{* *}$. ${ }^{(3)} \mathrm{y}=4,49 \mathrm{x}+2 \cdot 261 \mathrm{R}^{2}=0,79^{* *}$. ${ }^{(4)} \mathrm{y}=0,03 \mathrm{x}+33,6 \mathrm{R}^{2}=0,68^{* *}$.

${ }^{(5)} \mathrm{y}=0,00057 \mathrm{x}^{2}+0,14 \mathrm{x}+32,2 \mathrm{R}^{2}=0,98^{* *} .{ }^{(6)} \mathrm{y}=0,02 \mathrm{x}+7,9 \mathrm{R}^{2}=0,91^{* *} .{ }^{(7)} \mathrm{y}=0,005 \mathrm{x}+4,8 \mathrm{R}^{2}=0,55^{* *}$. ns Não-significativo. ${ }^{*} \mathrm{e}^{* *}$ Significativo a 5 e $1 \%$ de probabilidade, respectivamente. 
contribuiu para mineralização da matéria orgânica do solo, ou pela eficiência na fixação biológica de $\mathrm{N}$ atmosférico.

Entre os componentes da produção, o número de vagens por planta e o número de grãos por vagem sofreram influência das doses de adubação nitrogenada, em anos distintos (Tabela 2). O número de vagens por planta foi maior no segundo ano experimental, independentemente do manejo de solo ou das doses de adubação nitrogenada. Segundo Gomes et al. (2000), quando o feijoeiro é cultivado sob condições de sequeiro e com deficiência hídrica, o componente da produção mais afetado é o número de vagens por planta. Nos dois anos, houve redução da precipitação pluvial no mês de fevereiro, mais acentuada no primeiro ano, com volume total de $161 \mathrm{~mm}$, que coincidiu com os estádios fenológicos de florescimento pleno e enchimento de vagens, porém sem comprometer o desenvolvimento do feijoeiro.

Em relação ao número de grãos por vagem, Didonet (2002) verificou efeito negativo de temperaturas altas $\left(37^{\circ} \mathrm{C}\right.$ durante o dia e $25^{\circ} \mathrm{C}$ à noite, durante 72 horas). Nas condições experimentais, o número de grãos por vagem praticamente não variou de um ano para outro, apesar do manejo de solo ou das doses de adubação nitrogenada. A temperatura máxima no mês de fevereiro, nos dois anos experimentais, foi de $28^{\circ} \mathrm{C}$.

A massa de 100 grãos foi influenciada tanto pelo manejo de solo quanto pelas doses de adubação nitrogenada, mas apenas no primeiro ano (Tabela 3). O maior valor determinado no preparo convencional concorda com Stone \& Moreira (2001), que verificaram acréscimo nesse componente, com o aumento das doses de $\mathrm{N}$ em cobertura, com resposta reduzida no sistema de plantio direto (cultivar Aporé, no período de inverno), quando comparado aos sistemas de arado de aiveca e grade aradora. Arf et al. (2004) obtiveram melhor resultado no plantio direto, que diferiu do preparo com arado de aiveca no primeiro ano de cultivo, para a cultivar IAC Carioca Eté, no inverno. Para as doses de N, os valores ajustaram-se a uma equação linear crescente (Tabela 3), o que está de acordo com o obtido por Chidi et al. (2002), em que a maior dose de $\mathrm{N}$ proporcionou o valor de 20,8 g, para a cultivar IAC Carioca, no inverno. No entanto, Silva et al. (2003) não obtiveram resposta semelhante com a aplicação de doses de até $150 \mathrm{~kg} \mathrm{ha}^{-1}$ de $\mathrm{N}$, da mesma forma que Arf et al. (2004), que variaram as doses de 0 a $120 \mathrm{~kg} \mathrm{ha}^{-1}$ de $\mathrm{N}$.

Quanto à produtividade de grãos (Tabela 3) no segundo ano experimental, o maior valor foi obtido pelo preparo convencional, em relação ao plantio direto, e o maior número de vagens por planta deve ter contribuído para tal resultado, mesmo não havendo diferença significativa entre os manejos de solo (Tabela 2).

Nos dois anos, a adubação nitrogenada influenciou os valores da produtividade de grãos. No primeiro ano

Tabela 3. Massa de 100 grãos, produtividade e teor de proteína bruta nos grãos do feijoeiro, em função da adubação nitrogenada de cobertura, em dois sistemas de manejo de solo, em 2003 e $2004^{(1)}$.

\begin{tabular}{|c|c|c|c|c|c|c|}
\hline \multirow[t]{2}{*}{ Tratamento } & \multicolumn{2}{|c|}{ Massa de 100 grãos (g) } & \multicolumn{2}{|c|}{$\begin{array}{l}\text { Produtividade de grãos } \\
\qquad\left(\mathrm{kg} \mathrm{ha}^{-1}\right)\end{array}$} & \multicolumn{2}{|c|}{ Teor de proteína bruta (\%) } \\
\hline & $2003^{(2)}$ & 2004 & $2003^{(3)}$ & $2004^{(4)}$ & $2003^{(5)}$ & $2004^{(6)}$ \\
\hline \multicolumn{7}{|l|}{ Manejo } \\
\hline $\mathrm{PC}$ & $30,10 \mathrm{a}$ & 32,40 & 1.656 & $2.872 \mathrm{a}$ & 22,50 & 19,50 \\
\hline PD & $28,90 \mathrm{~b}$ & 32,70 & 1.868 & $2.656 \mathrm{~b}$ & 22,70 & 21,20 \\
\hline Teste F & $42,50^{*}$ & $0,17^{\mathrm{ns}}$ & $7,41^{\mathrm{ns}}$ & $20,31^{*}$ & $0,14^{\mathrm{ns}}$ & $4,77^{\mathrm{ns}}$ \\
\hline CV $(\%)$ & 1,80 & 6,90 & 13,90 & 5,50 & 5,50 & 11,70 \\
\hline \multicolumn{7}{|c|}{ Dose de $N\left(\mathrm{~kg} \mathrm{ha}^{-1}\right)$} \\
\hline 0 & 28,40 & 32,60 & 1.665 & 2.420 & 22,20 & 19,20 \\
\hline 40 & 28,40 & 31,80 & 1.726 & 2.573 & 21,20 & 18,60 \\
\hline 80 & 27,70 & 31,80 & 1.915 & 2.724 & 23,20 & 20,40 \\
\hline 120 & 30,80 & 32,90 & 1.878 & 3.029 & 21,80 & 21,20 \\
\hline 160 & 32,80 & 33,70 & 1.627 & 3.072 & 24,60 & 22,40 \\
\hline Teste F & $11,22^{* *}$ & $2,42^{\mathrm{ns}}$ & $4,65^{* * 2}$ & $53,37^{* *}$ & $3,44^{*}$ & $6,30^{* *}$ \\
\hline$M \times D$ & $1,66^{\mathrm{ns}}$ & $2,18^{\mathrm{ns}}$ & $1,33^{\mathrm{ns}}$ & $11,85^{* *}$ & $0,68^{\mathrm{ns}}$ & $0,14^{\mathrm{ns}}$ \\
\hline CV (\%) & 6,50 & 4,40 & 9,50 & 3,90 & 9,10 & 8,50 \\
\hline
\end{tabular}

${ }^{(1)}$ Médias seguidas de letras distintas diferem entre si, pelo teste de Tukey a 1\% de probabilidade; PC: preparo convencional; PD: plantio direto. ${ }^{(2)} \mathrm{y}=0,03 \mathrm{x}+27,3 \mathrm{R}^{2}=0,62^{* *} .{ }^{(3)} \mathrm{y}=0,04 \mathrm{x}^{2}+6,25 \mathrm{x}+1.626 \mathrm{R}^{2}=0,79^{* *} .{ }^{(4)} \mathrm{y}=4,39 \mathrm{x}+2.412 \mathrm{R}^{2}=0,96^{* *} .{ }^{(5)} \mathrm{y}=0,01 \mathrm{x}+21,5 \mathrm{R}^{2}=0,65^{*}$. (6) $\mathrm{y}=0,02 \mathrm{x}+18,5 \mathrm{R}^{2}=0,86^{* *}$. ns Não-significativo. ${ }^{*} \mathrm{e}{ }^{* *}$ Significativo a 5 e $1 \%$ de probabilidade, respectivamente. 
observou-se uma função quadrática. A produtividade máxima de $1.870 \mathrm{~kg} \mathrm{ha}^{-1}$ foi obtida com a dose de $78 \mathrm{~kg} \mathrm{ha}^{-1}$ de $\mathrm{N}$, que promoveu acréscimo de $12 \%$, em relação à não-aplicação de $\mathrm{N}$ em cobertura. No segundo ano, o aumento das doses de $\mathrm{N}$ em cobertura propiciou elevação nos valores de produtividade de grãos (Tabela 3). Nesse ano também foi estabelecida interação significativa, com resposta linear para doses de $\mathrm{N}$ no plantio direto, e quadrática no preparo convencional, em que a dose de $160 \mathrm{~kg} \mathrm{ha}^{-1}$ de $\mathrm{N}$ não permitiu a máxima produtividade, que somente seria alcançada com a aplicação de $185 \mathrm{~kg} \mathrm{ha}^{-1}$ de N (Figura 1).

Os resultados do primeiro ano reforçam, de certa forma, os obtidos por Silveira \& Damasceno (1993), e Chidi et al. (2002), que alcançaram no preparo convencional, em semeadura de inverno, produtividade máxima com as doses de 72 e $76 \mathrm{~kg} \mathrm{ha}^{-1}$ de $\mathrm{N}$, com as cultivares Carioca e IAC Carioca, respectivamente. No entanto, Stone \& Moreira (2001) utilizaram a cultivar Aporé e verificaram que a maior dose de $\mathrm{N}$, aplicada em cobertura (120 kg ha-1 de $\mathrm{N}$ ), não foi suficiente para atingir máximo potencial produtivo da cultura, que seria obtido com $137 \mathrm{~kg} \mathrm{ha}^{-1} \mathrm{de} \mathrm{N}$. Carvalho et al. (2003), por sua vez, estimaram que a produtividade máxima também seria alcançada com dose superior a $140 \mathrm{~kg} \mathrm{ha}^{-1}$ de $\mathrm{N}$, refor-

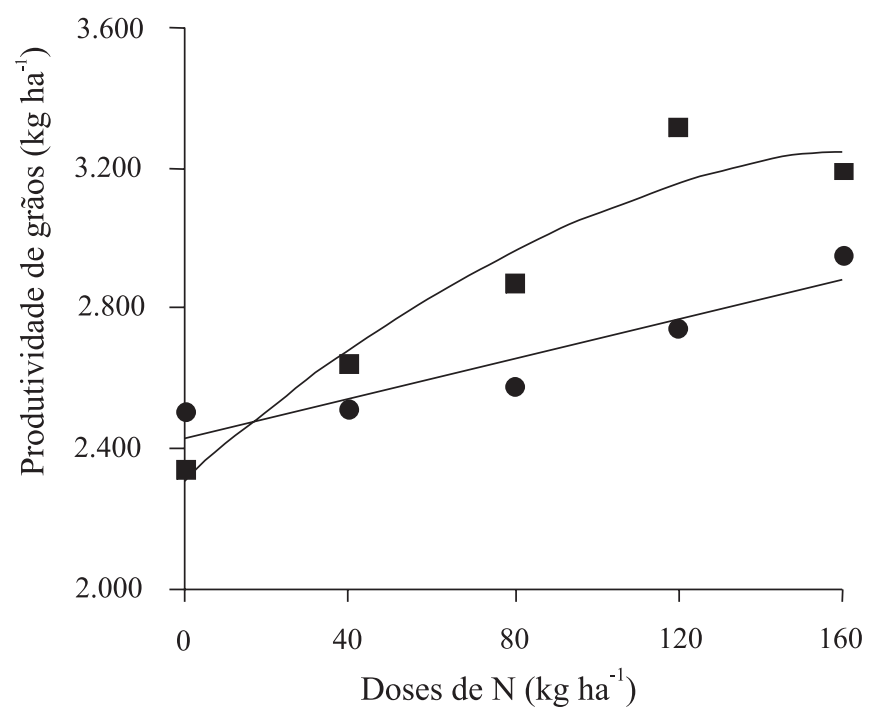

Figura 1. Produtividade de grãos do feijoeiro, em função da adubação nitrogenada de cobertura, em dois sistemas de manejo de solo: plantio direto (PD, O) e preparo convencional (PC, घ), em 2004. çando a necessidade de doses maiores no plantio direto, o que está intimamente relacionado com a decomposição de restos culturais.

A produtividade de grãos do feijão também é influenciada pelo regime hídrico, o qual pode afetar o crescimento do sistema radicular e, conseqüentemente, a absorção e translocação de nutrientes (Gomes et al., 2000). Nos dois anos experimentais, o total de precipitação pluvial foi adequado para o desenvolvimento da cultura, contudo, nos meses de janeiro de 2003 e 2004, foi observada precipitação pluvial acumulada de aproximadamente 400 e $300 \mathrm{~mm}$, respectivamente; ou seja, similar à lâmina de água que a cultura do feijão necessita para completar todo o seu ciclo e se desenvolver de forma satisfatória. Essa maior precipitação pluvial, em janeiro de 2003, período em que foi realizada a adubação de cobertura, pode ter comprometido a eficiência da adubação nitrogenada, em função da maior perda do nutriente por lixiviação, que se refletiu numa produtividade inferior à de 2004.

Em 2004, houve maior produtividade de grãos, o que pode estar relacionado ao maior número de vagens por planta, à massa de 100 grãos e ao fato de no segundo ano do sistema de sucessão de culturas (aveia-preta/milheto/ feijão) ter aumentado a disponibilidade de nutrientes, com melhoria nas condições do solo, aliado a práticas culturais adequadas (Tabelas 2 e 3).

Houve acréscimo do teor de proteína bruta (Tabela 3), à medida que aumentaram as doses de $\mathrm{N}$, possivelmente proporcionando a translocação desse elemento das folhas para os grãos. Bordin et al. (2003) obtiveram, com a cultivar Pérola, no período de inverno, valor de $24 \%$ de proteína bruta, com a utilização da dose de $75 \mathrm{~kg} \mathrm{ha}^{-1}$ de $\mathrm{N}$, resultado semelhante ao deste trabalho. Verificou-se, no entanto, que no segundo ano houve maior produtividade, porém menor teor de proteína bruta, comparativamente ao primeiro ano. Esses resultados corroboram os de Pompeu (1993), que relatou que o teor de proteína bruta correlacionou-se negativamente com a produtividade de grãos.

\section{Conclusão}

A cultura do feijão responde às doses de nitrogênio em cobertura, com maior produtividade de grãos, no segundo ano da sucessão aveia-preta/milheto/feijão, necessitando, porém, de doses mais elevadas no sistema de plantio direto. 


\section{Referências}

ALMEIDA, C. de; CARVALHO, M.A.C. de; ARF, O.; SÁ, M.E. de; BUZETTI, S. Uréia em cobertura e via foliar em feijoeiro. Scientia Agricola, v.57, p.293-298, 2000.

AMBROSANO, E.J.; TANAKA, R.T.; MASCARENHAS, H.A.A.; RAIJ, B. van; QUAGGIO, J.A.; CANTARELLA, H. Leguminosas e oleaginosas. In: RAIJ, B. van; CANTARELA, H.; QUAGGIO, J.A.; FURLANI, A.M.C. (Ed.). Recomendações de adubação e calagem para o Estado de São Paulo. 2.ed. rev. Campinas: IAC, 1997. p.189-203. (Boletim técnico, 100).

ARF, O. Importância da adubação na qualidade do feijão e caupi. In: SÁ, M.E. de; BUZETTI, S. (Ed.). Importância da adubação na qualidade dos produtos agrícolas. São Paulo: Ícone, 1994. p.233255.

ARF, O.; RODRIGUES, R.A.F.; SÁ, M.E. de; BUZETTI, S.; NASCIMENTO, V. do. Manejo do solo, água e nitrogênio no cultivo de feijão. Pesquisa Agropecuária Brasileira, v.39, p.131-138, 2004. BALBINO, L.C.; MOREIRA, J.A.A.; SILVA, J.G. da; OLIVEIRA, E.F. de; OLIVEIRA, I.P. de. Plantio direto. In: ARAÚJO, R.S.; RAVA, C.A.; STONE, L.F.; ZIMMERMANN, M.J. de O. (Coord.). Cultura do feijoeiro comum no Brasil. Piracicaba: Potafos, 1996. p.301-352.

BORDIN, L.; FARINELLI, R.; PENARIOL, F.G.; FORNASIERI FILHO, D. Sucessão de cultivo de feijão-arroz com doses de adubação nitrogenada após adubação verde, em semeadura direta. Bragantia, v.62, p.417-428, 2003.

CARVALHO, M.A.C.; FURLANI JUNIOR, E.; ARF, O.; SÁ, M.E. de; PAULINO, H.B.; BUZETTI, S. Doses e épocas de aplicação de nitrogênio e teores foliares deste nutriente e de clorofila em feijoeiro. Revista Brasileira de Ciência do Solo, v.27, p.445-450, 2003.

CHIDI, S.N.; SORATTO, R.P.; SILVA, T.R.B. da; ARF, O.; SÁ, M.E. de; BUZETTI, S. Nitrogênio via foliar e em cobertura em feijoeiro irrigado. Acta Scientiarum: Agronomia, v.24, p.1391-1395, 2002.

DIDONET, A.D. Respostas da cultivar de feijoeiro comum Pérola ao choque térmico com altas temperaturas. Santo Antônio de Goiás: Embrapa Arroz e Feijão, 2002. 4p. (Comunicado técnico, 39).

EMBRAPA. Centro Nacional de Pesquisa de Solos (Rio de Janeiro, RJ). Sistema brasileiro de classificação dos solos. Brasília: Embrapa-SPI; Embrapa-CNPS, 1999. 412p.

FERNÁNDEZ, F.; GEPTS, P.; LÓPEZ, M. Etapas de desarrollo en la planta de frijol. In: LÓPEZ, M.; FERNÁNDEZ, F.;
SCHOONHOVEN, A. van (Ed.). Frijol: investigación y producción. Cali, Colombia: CIAT, 1985. p.61-78.

GOMES, A.A.; ARAÚJO, A.P.; ROSSIELLO, R.O.P.; PIMENTEL, C. Acumulação de biomassa, características fisiológicas e rendimento de grãos em cultivares de feijoeiro irrigado e sob sequeiro. Pesquisa Agropecuária Brasileira, v.35, p.1927-1937, 2000.

MALAVOLTA, E.; VITTI, G.C.; OLIVEIRA, S.A. (Ed.). Avaliação do estado nutricional de plantas: princípios e aplicações. 2.ed. Piracicaba: Potafos, 1997. 319p.

POMPEU, A.S. Feijão. In: FURLANI, A.M.C.; VIÉGAS, G.P. (Ed.). O melhoramento de plantas no Instituto Agronômico. Campinas: Instituto Agronômico, 1993. p.111-155.

ROSOLEM, C.A. Calagem e adubação mineral. In: ARAÚJO, R.S.; RAVA, C.A.; STONE, L.F.; ZIMMERMANN, M.J.O. (Coord.). Cultura do feijoeiro comum no Brasil. Piracicaba: Potafos, 1996. p.353-390.

SALTON, J.C.; HERNANI, L.C.; NOVACHINSKI, J.R.; FONTES, C.Z. (Org.). Sistema plantio direto: o produtor pergunta, a Embrapa responde. Brasília, DF: Embrapa-SPI; Dourados, MS: EmbrapaCPAO, 1998. 248p. (Coleção 500 perguntas, 500 respostas).

SARRUGE, J.R.; HAAG, H.P. Análises químicas em plantas. Piracicaba: Esalq, 1974. 56p.

SILVA, T.R.B. da; ARF, O.; SORATTO, R.P. Adubação nitrogenada e resíduos vegetais no desenvolvimento do feijoeiro em sistema de plantio direto. Acta Scientiarum: Agronomia, v.25, p.81-87, 2003.

SILVEIRA, P.M. da; DAMASCENO, M.A. Doses e parcelamento de K e de N na cultura do feijoeiro irrigado. Pesquisa Agropecuária Brasileira, v.28, p.1269-1276, 1993.

SIQUEIRA, J.O.; MOREIRA, F.M. de S. Transformações bioquímicas e ciclos dos elementos no solo. In: MOREIRA, F.M. de S.; SIQUEIRA, J.O. (Ed.). Microbiologia e bioquímica do solo. Lavras: Ed. da Ufla, 2002. p.305-329.

STONE, L.F.; MOREIRA, J.A.A. Efeitos de sistemas de preparo do solo no uso da água e na produtividade do feijoeiro. Pesquisa Agropecuária Brasileira, v.35, p.835-841, 2000.

STONE, L.F.; MOREIRA, J.A.A. Resposta do feijoeiro ao nitrogênio em cobertura, sob diferentes lâminas de irrigação e preparos de solo. Pesquisa Agropecuária Brasileira, v.36, p.473-481, 2001.

YOKOYAMA, L.P. Aspectos conjunturais da produção de feijão. In: AIDAR, H.; KLUTHCOUSKI, J.; STONE, L.F. (Ed.). Produção do feijoeiro comum em várzeas tropicais. Santo Antônio de Goiás: Embrapa Arroz e Feijão, 2002. p.249-292.

Recebido em 11 de novembro de 2004 e aprovado em 22 de junho de 2005 